\title{
UTILIZAÇÃO DE AMBIENTES VIRTUAIS DE ENSINO E APRENDIZAGEM: UM COMPARATIVO ENTRE DIFERENTES MODALIDADES DE ENSINO PARA JOVENS E ADULTOS DO IFTO - CAMPUS PALMAS
}

\author{
USE OF VIRTUAL ENVIRONMENTS FOR TEACHING AND LEARNING: A \\ COMPARATIVE BETWEEN DIFFERENT METHODS OF TEACHING FOR YOUNG \\ AND ADULTS THE IFTO - PALMAS CAMPUS
}

\author{
Anderson Rodrigo Piccini ${ }^{1}$ \\ Ana Maria Denardi ${ }^{2}$ \\ Gerson Pesente Focking ${ }^{3}$
}

\section{RESUMO}

O grande avanço tecnológico associado ao barateamento dos equipamentos de informática proporcionou a oportunidade de ampliar os horizontes do ensino tradicional para além do espaço físico da sala de aula. Diante deste panorama, tornou-se necessário organizar novas experiências educacionais em que se introduzam tecnologias que possam ser utilizadas em processos cooperativos de aprendizagem, tornado-a mais significativa na medida em que maior for o grau de interação e comunicação entre os participantes do processo. A integração entre professor-aluno pode ser positivamente alterada pelo uso criativo dessas tecnologias, mas para que isso aconteça é importante haver incentivo e treinamento necessário, para que os professores passem pela experiência deste contato e tornem-se multiplicadores, expandindo essas experiências para seus alunos. Quanto maior o contato com a tecnologia por parte dos professores, maior será a incorporação de novos ambientes e a utilização de ferramentas virtuais como forma de ampliar positivamente o processo de ensino e aprendizagem. Para que isso aconteça, é importante que esse aluno receba o direcionamento que the proporcione uma busca correta em razão da sua formação. Neste contexto, o professor deve 
apresentar-se como mediador e facilitador no processo de interação, propiciando momentos de construção coletiva.

PALAVRAS-CHAVE: Tecnologia da Informação e Comunicação (TIC) - ferramentas virtuais - educação de jovens e adultos.

\section{ABSTRACT:}

The great technological advances associated with the lower prices of computer equipment provided an opportunity to enlarge his horizons beyond the traditional teaching of the physical space of the classroom. Against this panorama, it became necessary to organize new educational experiences in which they introduce technologies that can be used in cooperative learning processes, making it more significant to the extent that greater the degree of interaction and communication between process participants. The integration of teacher-student can be positively changed by the creative use of these technologies, but for that to happen it is important to have encouragement and training necessary for teachers to pass through the experience of this contact and become multipliers, expanding these experiences for their students. The greater contact with technology by teachers, the greater the incorporation of new environments and the use of virtual tools for enhanced positively the process of teaching and learning. For this to happen, it is important that students receive the guidance that gives a correct search because of their training. In this context, the teacher should present himself as a mediator and facilitator in the process of interaction, providing moments of collective construction.

KEYWORDS: Information and Communication Technology (ICT) - virtual tools education youth and adults.

\section{INTRODUÇÃO}

As transformações do mundo moderno trouxeram consigo novas exigências, substituindo a procura de simples mão de obra qualificada pela procura 
de sujeitos autônomos, criativos e críticos, que tenham capacidade de trabalhar em equipe, que buscam informações e as transformam em conhecimento.

Este trabalho procurou levantar algumas ferramentas virtuais de ensino e aprendizagem existentes, que podem ser disponibilizadas para auxiliar a aprendizagem de jovens e adultos e entender em que proporção são utilizadas por parte dos professores do PROEJA e EAD do IFTO - campus Palmas.

O objetivo deste trabalho foi buscar ferramentas de aprendizagem disponíveis na internet que possam auxiliam professores do PROEJA e EAD do IFTO - Campus Palmas e perceber como o processo de inclusão dessas ferramentas como auxílio no ensino e aprendizagem se dá em maior ou menor proporção, conforme o contato por parte dos professores com essas novas tecnologias.

O aumento e a evolução da tecnologia, associado ao barateamento dos computadores pessoais e portáteis, tornaram o acesso à internet (a rede mundial de computadores) muito mais simples e prático, proporcionando a uma grande parte da população o acesso à rede, para se informar e buscar conhecimento. Diante deste panorama ressalta-se a importância da reestrutura da relação ensino aprendizagem, para incluir esse novo conceito de forma positiva, ampliando as possibilidades de novas descobertas, tanto por parte dos professores como por parte dos alunos.

\section{REVISÃO DA LITERATURA}

\subsection{A IMPORTÂNCIA DA TECNOLOGIA PARA AMPLIAR OS HORIZONTES DO APRENDIZADO}

Estudar não é um ato de consumir idéias, mas de criá-las e recriálas. FREIRE (1982, p. 09-12).

O mundo contemporâneo, após constantes transformações, criou a necessidade da busca por sujeitos criativos e colaborativos que tenham qualidades 
que vão além de mão de obra qualificada. Essa idéia, baseada no artigo 37 da lei 9.394 de 20 de dezembro de 1996, atualizado pela lei no 11.741 , de 16 de julho de 2008 (Lei de Diretrizes e Bases da Educação Nacional), sugere que a educação de jovens e adultos deve ter como objetivo cumprir de maneira satisfatória sua função de prepará-los para o exercício de cidadania e para o mundo do trabalho. Valente (1999) endossa a cobrança da sociedade na mudança do novo paradigma educacional, que exige dos cidadãos uma postura autônoma, criativa, crítica e reflexiva, capazes de aprender a aprender, saber pensar, saber tomar decisões e saber buscar a informação de que necessitam, percebendo sua importância dentro da sociedade e refletindo sobre seu papel, construindo seu próprio conhecimento através desses conceitos.

Paulo Freire defendia a idéia da educação libertadora baseada na valorização da linguagem popular, no diálogo e na conscientização, sendo contra o assistencialismo, a domesticação e o autoritarismo. Ele acreditava que a partir da alfabetização dos jovens e adultos, que os tornassem cidadãos plenos, ocorreria verdadeiramente uma mudança social. Além disso, Freire (2002, p. 25) afirmava que "[...] ensinar não é apenas transferir conhecimento, mas sim criar as possibilidades para sua produção ou a sua construção".

Surgem nesta discussão os benefícios do uso de tecnologias associadas ao processo educacional, ampliando o campo de atuação entre professores e alunos para além da escola clássica entre os muros escolares e da sala de aula tradicional. Fica desta forma aumentado o espaço profissional dos professores em diferentes frentes de atuação. As tecnologias ampliam as possibilidades de ensino para além do curto espaço da presença física do professor e alunos na mesma sala de aula prolongando o espaço de conhecimento.

As tecnologias, quando difusamente utilizadas, são recursos que ampliam os limites da sala de aula desde que utilizadas de modo planejado. Surge assim a necessidade de reforçar a importância do planejamento pedagógico e conhecer as diferentes ferramentas disponibilizadas na internet para este contexto, adequando o uso dessas tecnologias em atividades de ensino.

Observado por FLORES (1996 apud BÖELTER, 2009, p. 5) afirma que: 
A informática deve habilitar e dar oportunidade ao aluno de adquirir novos conhecimentos, facilitar o processo de ensino/aprendizagem, enfim ser um complemento de conteúdos curriculares visando o desenvolvimento integral do individuo.

Com a expansão das tecnologias de comunicação e informação em todos os ramos da sociedade ocorreram muitas mudanças no modo de ensinar e aprender. Informações chegam através de diferentes mídias, criam referenciais e transformam-se em elos para novas descobertas.

Neste cenário tornou-se necessário organizar novas experiências educacionais em que se introduzam tecnologias que possam ser utilizadas em processos cooperativos de aprendizagem tornado-a mais significativa na medida em que maior for o grau de interação e comunicação entre os participantes do processo.

Segundo BARCELOS (2009, p. 13) em seu artigo sobre Internet: um novo paradigma na educação de jovens adultos:

O papel específico do professor na era da conectividade é o de desenvolver processos cognitivos em situações de aprendizagem que fazem uso de interações bem como de mediador e facilitador dessas interações. É necessário estimular a pesquisa como um campo de aprendizagem para projetos apoiados em mídias interativas e o professor, então, atua como um orientador desses projetos.

A integração entre o professor e o aluno pode ser profundamente alterada pelo uso criativo dessas tecnologias, onde o professor é auxiliado a transformar o isolamento e a indiferença na participação dos alunos nas salas de aulas em interesse e colaboração de cidadãos participativos, inseridos num mundo globalizado. 


\title{
2.2NOVAS TECNOLOGIAS: VANTAGENS ADVINDAS DE SUA UTILIZAÇÃO.
}

\author{
Segundo BARANAUSKAS (2000 apud BÖELTER, 2009, p. 18):
}

\begin{abstract}
O grande avanço tecnológico atual, as redes de computadores, em especial a internet que permite conectar pessoas espalhadas pelo mundo todo, tem sido o novo impulso e a nova promessa em direção ao uso da tecnologia de computadores para um entendimento mais amplo de educação e da consciência de sermos "cidadãos do mundo". A tecnologia de redes de computadores viabiliza funções em que não só os estudantes, mas os próprios professores possam desenvolver suas atividades de modo colaborativo.
\end{abstract}

Com o uso constante das ferramentas disponíveis na rede mundial de computadores, a sala de aula se expande e incorpora novos ambientes que interagem e fortalecem a relação de ensino-aprendizagem. As ferramentas disponibilizadas através do avanço tecnológico podem ser utilizadas em todas as modalidades de ensino tanto presencial, virtual ou de forma mista (complementando um ao outro).

Sendo a internet um grande meio de comunicação sem um poder central controlador e regulamentos específicos, é aberta a exploração de diversas possibilidades de descobrimento e a interatividade entre computadores e pessoas de diversos lugares do mundo.

Os ambientes virtuais de aprendizagem surgem como um ambiente que permite integrar mídias, linguagens e recursos, apresenta informações de maneira organizada e desenvolve interações entre pessoas e objetos. As tecnologias de informação e comunicação aparecem para os docentes como apoio no desenvolvimento do processo de ensino e aprendizagem propiciando momentos de construção coletiva.

Para que as novas tecnologias possam ser utilizadas, torna-se essencial a reformulação de programas pedagógicos, a reestruturação da gestão da educação com flexibilização das estruturas, a interdisciplinaridade e a transdisciplinaridade dos 
conteúdos, o relacionamento das instituições com outras esferas sociais e com a comunidade de modo global.

\subsection{AMBIENTES VIRTUAIS DE APRENDIZAGEM X AGENTES ENVOLVIDOS NO PROCESSO DE APRENDIZAGEM.}

O avanço tecnológico possibilita uma nova realidade educacional: o ensino mediado por computador. A inserção do computador na educação provoca uma mudança de comportamento e faz com que a sala de aula perca gradativamente suas fronteiras. Observado por Lévy (1999), as tecnologias do ciberespaço ampliam, estimulam e alteram muitas funções cognitivas humanas através das tecnologias computacionais, tais como: a memória (bancos de dados e hipertextos), a imaginação (simulações), a percepção (ambientes interativos e imersivos), os raciocínios (inteligência artificial), que favorecem novas formas de acesso à informação.

O ambiente virtual propicia o resgate de uma postura mais ativa dos agentes envolvidos. O professor deixa de ser detentor de todo o conhecimento para se transformar em um mediador das atividades de aprendizagem. $O$ estudo adquire maior flexibilidade, podendo ser realizado de acordo com a disponibilidade de tempo do aluno e no local mais adequado.

O desenvolvimento de materiais didáticos para uso nesses ambientes virtuais exige conhecimentos de diversas áreas tais como: informática, programação visual, psicologia da aprendizagem e conhecimento do conteúdo específico a ser ensinado, pressupondo a existência de uma equipe transdisciplinar, levando o professor a uma reformulação de suas práticas e métodos de ensino.

É fundamental fornecer suporte na preparação do professor para exercer suas funções neste novo ambiente, aproveitando ao máximo os recursos oferecidos pelas plataformas de desenvolvimento de ambientes virtuais. O professor deve estar preparado para se relacionar com seus alunos através da interface computacional e, para isso, ele precisa dominar as ferramentas disponíveis. 


\section{MATERIAL E MÉTODOS}

A pesquisa aqui apresentada tem como base a aplicação de questionários com educadores da modalidade PROEJA e do EAD (educação à distância), ambos do IFTO - campus Palmas. O objetivo é ter índices comparativos entre essas duas modalidades de ensino, buscando saber o que os professores julgam importante ter em um ambiente virtual, programa, sítio ou página da internet, para auxiliar os alunos a compreender melhor a disciplina ministrada em sala de aula e entender se realmente os professores utilizam das tecnologias disponíveis nos ambientes virtuais de ensino e aprendizagem. Após a aplicação, os questionários foram analisados, traduzidos através de porcentagens e apresentados em forma de tabelas e gráficos.

O questionário foi dividido em três partes sendo que:

A primeira questão apresentava uma lista de ferramentas e recursos onde deveriam ser atribuídos valores de uma escala de 1 a 5 (conforme modelo apresentado abaixo) os quais os professores julgassem ser importantes no processo de ensino e aprendizagem. A questão 01 aplicada foi a seguinte:

Sabe-se que a internet hoje disponibiliza vários recursos capazes de auxiliar no processo de ensino e aprendizagem, com base nesses recursos sítios ou sistemas de simulação online que podem ser utilizados:

1 - Por favor, enumere de 1 a 5 conforme orientação abaixo os recursos listados que você acredita serem capazes de auxiliar no processo de ensinoaprendizagem:

(1) - não conheço.

(2) - não é necessário ter;

(3) - indiferente, pode ou não ter;

(4) - é importante que tenha;

(5) - Indispensável, é muito importante e não pode faltar de maneira nenhuma. 
A - ( ) Questionários sobre assuntos ministrados;

B - ( ) Questionários com as respostas;

C - ( ) Questionários com as respostas comentadas;

D - ( ) Animações em flash;

E - ( ) Áudio sobre aulas ministradas;

F - ( ) Vídeo-aula sobre assuntos específicos;

G - ( ) Tutoriais para realização de experiências praticas em laboratório;

H - ( ) Simuladores ou softwares para realização de experiências dos efeitos físicos estudados;

I - ( ) Glossário de termos relacionados ao assunto;

J - ( ) Atividades de sistematização da aprendizagem (individuais ou em grupo) questionários, tarefas, entre outros

K - ( ) Conteúdo de estudo complementar para aprofundamento do tema - leituras complementares, indicações de sites úteis e recomendação de bibliografias utilizado em todas as temáticas, com variação dos tipos.

L - ( ) Chat;

M - ( ) Link para página externa, link a um arquivo

$\mathrm{N}$ - ( ) Arquivos de texto sobre os assuntos ministrados.

O - ( ) Repositório com arquivos (em geral) de apresentações e outros;

P - ( ) Simulados mediados por computador ------Testes ou Provas online;

Q - ( ) Acesso a redes sociais que falam sobre Física; Orkut, MySpace, Twitter;

R - ( ) Local dedicado para postagem de Duvidas, com opção para outras pessoas postarem respostas; Fórum

S - ( ) Acesso e edição colaborativa de conteúdo: Blogs e Wikis sobre Física;

T - ( ) Acesso a Comunicação: Skype, Messenger, Gmail;

U - ( ) Compartilhamento de arquivos: textos, planilhas e apresentações (Google Docs, Slideshare, Zoho); fotos (Flickr); vídeos (Youtube) e arquivos diversos, incluindo áudio e vídeo (4shared); 
V - ( ) Acesso a grupos de discussão: Yahoogroups;

W - ( ) Compartilhamento e edição online de imagens: Adobe Photoshop Express;

A segunda questão, a ser respondida de forma descritiva, tinha o objetivo de conhecer ambientes virtuais já utilizados pelos professores. A questão 02 aplicada foi seguinte:

2. Você já utilizou algum site que contenha algumas das ferramentas descritas acima e já recomendou este site para os alunos ampliar seus conhecimentos ou ate mesmo para tirar duvidas das aulas ministradas? Por favor, indique quais são os sites e quais as ferramentas encontradas:

A terceira e última questão, também a ser respondida de forma descritiva, procurou saber a aceitação dos professores perante as novas tecnologias. A questão 03 aplicada foi a seguinte:

3. Você acredita que o conteúdo da internet pode auxiliar seus alunos a aprender mais sobre os assuntos ministrados? Por favor, uma breve justificativa.

A aplicação do questionário ocorreu no período entre os dias 01/11/10 a 21/11/10, no IFTO - campus Palmas, junto a todos os professores que ministram aulas na modalidade do EAD e ao mesmo número de professores que ministram aulas na modalidade PROEJA.

\section{RESULTADOS E ANÁLISES}

Os resultados encontrados após a aplicação das pesquisas foram analisados através de porcentagens com auxílio de programa específico e traduzidos em forma de tabela e gráficos. A tabela abaixo apresentam as porcentagens das opções (de 1 a 5) mais escolhidas para cada pergunta, caracterizando a opinião dos professores a respeito de cada ferramenta especificada.

Dentre os professores entrevistados obteve-se os seguintes resultados: 
Tabela 1 - Porcentagem das maiores respostas obtida na questão 1.

\begin{tabular}{|c|c|c|c|}
\hline \multirow[t]{2}{*}{ Questão } & \multicolumn{2}{|c|}{$\begin{array}{l}\text { Maior \% obtida nas } \\
\text { modalidades }\end{array}$} & \multirow[t]{2}{*}{ Opção escolhida } \\
\hline & PROEJA & EAD & \\
\hline $\begin{array}{l}\text { (A) Questionários sobre assuntos } \\
\text { ministrados }\end{array}$ & $60 \%$ & $53 \%$ & $\begin{array}{l}\text { Consideraram importante que } \\
\text { tenha (opção 4) }\end{array}$ \\
\hline \multirow{3}{*}{$\begin{array}{l}\text { (B) Questionários com as } \\
\text { Respostas }\end{array}$} & $40 \%$ & $80 \%$ & Consideraram importante que \\
\hline & & & \\
\hline & $40 \%$ & - & $\begin{array}{l}\text { Consideraram indiferentes } \\
\text { (opção 3) }\end{array}$ \\
\hline \multirow[t]{2}{*}{$\begin{array}{l}\text { (C) Questionários com as respostas } \\
\text { comentadas }\end{array}$} & $40 \%$ & - & $\begin{array}{l}\text { Consideraram Indispensável, } \\
\text { muito importante (opção 5) }\end{array}$ \\
\hline & - & $53 \%$ & $\begin{array}{l}\text { Consideraram importante que } \\
\text { tenha (opção 4) }\end{array}$ \\
\hline \multirow[t]{2}{*}{ (D) Animações em flash } & $66 \%$ & $40 \%$ & $\begin{array}{l}\text { Consideraram Indispensável, } \\
\text { muito importante (opção 5) }\end{array}$ \\
\hline & - & $40 \%$ & $\begin{array}{l}\text { Consideraram importante que } \\
\text { tenha (opção 4) }\end{array}$ \\
\hline \multirow[t]{5}{*}{ (E) Áudio sobre aulas ministradas } & $20 \%$ & $60 \%$ & $\begin{array}{l}\text { Consideraram indispensável, } \\
\text { muito importante (opção 5) }\end{array}$ \\
\hline & $20 \%$ & - & $\begin{array}{l}\text { Consideraram importante que } \\
\text { tenha (opção 4) }\end{array}$ \\
\hline & $20 \%$ & - & $\begin{array}{l}\text { Consideraram indiferente } \\
\text { (opção 3) }\end{array}$ \\
\hline & $20 \%$ & - & $\begin{array}{l}\text { Consideraram não necessário } \\
\text { (opção 2) }\end{array}$ \\
\hline & $20 \%$ & - & $\begin{array}{l}\text { Afirmam que não conhecem } \\
\text { (opção 1) }\end{array}$ \\
\hline (F) Vídeo-aula sobre assuntos específicos & $33 \%$ & $60 \%$ & $\begin{array}{l}\text { Consideraram importante que } \\
\text { tenha (opção 4) }\end{array}$ \\
\hline \multirow[t]{2}{*}{$\begin{array}{l}\text { (G) Tutoriais para realização de } \\
\text { experiências praticas em laboratório }\end{array}$} & - & $66 \%$ & $\begin{array}{l}\text { Consideraram indispensável, } \\
\text { muito importante (opção 5) }\end{array}$ \\
\hline & $46 \%$ & - & $\begin{array}{l}\text { Consideraram importante que } \\
\text { tenha (opção 4) }\end{array}$ \\
\hline
\end{tabular}




\begin{tabular}{|c|c|c|c|}
\hline $\begin{array}{l}\text { (H) Simuladores ou softwares para } \\
\text { realização de experiências dos efeitos } \\
\text { físicos estudados; }\end{array}$ & $26 \%$ & $53 \%$ & $\begin{array}{l}\text { Consideraram importante que } \\
\text { tenha (opção 4) }\end{array}$ \\
\hline \multirow[t]{2}{*}{$\begin{array}{l}\text { (I) Glossário de termos relacionados ao } \\
\text { assunto }\end{array}$} & - & $53 \%$ & $\begin{array}{l}\text { Consideraram indispensável, } \\
\text { muito importante (opção 5) }\end{array}$ \\
\hline & $53 \%$ & - & $\begin{array}{l}\text { Consideraram importante que } \\
\text { tenha (opção 4) }\end{array}$ \\
\hline \multirow{2}{*}{$\begin{array}{l}\text { (J) Atividades de sistematização da } \\
\text { aprendizagem (individuais ou em grupo) - } \\
\text { questionários, tarefas, entre outros }\end{array}$} & $40 \%$ & $40 \%$ & $\begin{array}{l}\text { Consideraram indispensável, } \\
\text { muito importante (opção 5) }\end{array}$ \\
\hline & - & $40 \%$ & $\begin{array}{l}\text { Consideraram importante que } \\
\text { tenha (opção 4) }\end{array}$ \\
\hline \multirow{2}{*}{$\begin{array}{l}\text { (K) Conteúdo de estudo complementar } \\
\text { para aprofundamento do tema - leituras } \\
\text { complementares, indicações de sites úteis } \\
\text { e recomendação de bibliografias utilizada } \\
\text { em todas as temáticas, com variação dos } \\
\text { tipos. }\end{array}$} & $73 \%$ & - & $\begin{array}{l}\text { Consideraram indispensável, } \\
\text { muito importante (opção 5) }\end{array}$ \\
\hline & - & $60 \%$ & $\begin{array}{l}\text { Consideraram importante que } \\
\text { tenha (opção 4) }\end{array}$ \\
\hline (L) Chat; & $40 \%$ & $53 \%$ & $\begin{array}{l}\text { Consideraram indiferente } \\
\text { (opção 3) }\end{array}$ \\
\hline \multirow[t]{2}{*}{$\begin{array}{l}\text { (M) Link para página externa, link a um } \\
\text { arquivo }\end{array}$} & - & $53 \%$ & $\begin{array}{l}\text { Consideraram importante que } \\
\text { tenha (opção 4) }\end{array}$ \\
\hline & $26 \%$ & - & $\begin{array}{l}\text { Consideraram indiferente } \\
\text { (opção 3) }\end{array}$ \\
\hline $\begin{array}{l}\text { (N) Arquivos de texto sobre os assuntos } \\
\text { ministrados. }\end{array}$ & $40 \%$ & $46 \%$ & $\begin{array}{l}\text { Consideraram importante que } \\
\text { tenha (opção 4) }\end{array}$ \\
\hline $\begin{array}{l}\text { (O) Repositório com arquivos (em geral) } \\
\text { de apresentações e outros; }\end{array}$ & $33 \%$ & $80 \%$ & $\begin{array}{l}\text { Consideraram importante que } \\
\text { tenha (opção 4) }\end{array}$ \\
\hline \multirow[t]{2}{*}{$\begin{array}{l}\text { (P) Simulados mediados por computador - } \\
\text { Testes ou Provas online; }\end{array}$} & $26 \%$ & - & $\begin{array}{l}\text { Consideraram indispensável, } \\
\text { muito importante (opção 5) }\end{array}$ \\
\hline & - & $60 \%$ & $\begin{array}{l}\text { Consideraram importante que } \\
\text { tenha (opção 4) }\end{array}$ \\
\hline \multirow[t]{2}{*}{$\begin{array}{l}\text { (Q) Acesso a redes sociais que falam } \\
\text { sobre a matéria; Orkut, MySpace, Twitter; }\end{array}$} & $26 \%$ & - & $\begin{array}{l}\text { Consideraram importante que } \\
\text { tenha (opção 4) }\end{array}$ \\
\hline & $26 \%$ & $66 \%$ & $\begin{array}{l}\text { Consideraram indiferente } \\
\text { (opção 3) }\end{array}$ \\
\hline $\begin{array}{l}\text { (R) Local dedicado para postagem de } \\
\text { Duvidas, com opção para outras pessoas }\end{array}$ & - & $66 \%$ & $\begin{array}{l}\text { Consideraram indispensável, } \\
\text { muito importante (opção 5) }\end{array}$ \\
\hline
\end{tabular}




\begin{tabular}{|c|c|c|c|}
\hline postarem respostas; Fórum & $46 \%$ & - & $\begin{array}{l}\text { Consideraram importante que } \\
\text { tenha (opção 4) }\end{array}$ \\
\hline $\begin{array}{l}\text { (S ) Acesso e edição colaborativa de } \\
\text { conteúdo: Blogs e Wikis sobre disciplina } \\
\text { ministrada. }\end{array}$ & $40 \%$ & $53 \%$ & $\begin{array}{l}\text { Consideraram importante que } \\
\text { tenha (opção 4) }\end{array}$ \\
\hline \multirow[t]{2}{*}{$\begin{array}{l}\text { (T) Acesso a Comunicação: Skype, } \\
\text { Messenger, Gmail; }\end{array}$} & $60 \%$ & $40 \%$ & $\begin{array}{l}\text { Consideraram importante que } \\
\text { tenha (opção 4) }\end{array}$ \\
\hline & - & $40 \%$ & $\begin{array}{l}\text { Consideraram indiferente } \\
\text { (opção 3) }\end{array}$ \\
\hline $\begin{array}{l}\text { (U) Compartilhamento de arquivos: textos, } \\
\text { planilhas e apresentações (Google Docs, } \\
\text { Slideshare, Zoho); fotos (Flickr); vídeos } \\
\text { (Youtube) e arquivos diversos, incluindo } \\
\text { áudio e vídeo (4shared); }\end{array}$ & $40 \%$ & $46 \%$ & $\begin{array}{l}\text { Consideraram importante que } \\
\text { tenha (opção 4) }\end{array}$ \\
\hline \multirow[t]{2}{*}{$\begin{array}{l}\text { (V) Acesso a grupos de discussão: } \\
\text { Yahoogroups; }\end{array}$} & $26 \%$ & $53 \%$ & $\begin{array}{l}\text { Consideraram importante que } \\
\text { tenha (opção 4) }\end{array}$ \\
\hline & $26 \%$ & - & $\begin{array}{l}\text { Consideraram indiferente } \\
\text { (opção 3) }\end{array}$ \\
\hline $\begin{array}{l}\text { (W) Compartilhamento e edição online de } \\
\text { imagens: Adobe Photoshop Express; }\end{array}$ & $46 \%$ & $53 \%$ & $\begin{array}{l}\text { Consideraram indiferente } \\
\text { (opção 3) }\end{array}$ \\
\hline
\end{tabular}

Comparando os dois grupos entrevistados percebe-se que o grupo de professores ligado à modalidade de ensino EAD utilizam e reconhecem mais ferramentas de ensino-aprendizagem ligados a tecnologia da informação. Essa afirmação tem como base a porcentagem de alternativas que receberam mais de $50 \%$ de aprovação dentre os 23 itens listados (consideradas importantes ou muito importantes), como mostra a tabela abaixo:

Tabela 2 - Questões que receberam maior aprovação.

\begin{tabular}{l|c|l}
\hline \multicolumn{1}{c|}{ Modalidade } & $\begin{array}{c}\text { Número de questões que } \\
\text { receberam mais de } 50 \% \\
\text { de aprovação }\end{array}$ & \multicolumn{1}{c}{ Questões } \\
\hline Professores do PROEJA & 5 & A;D;I;K;T; \\
\hline Professores EAD & 17 & A;B;C;D;E;F;G;H;I;J;K;M;O;P;R;S;V; \\
\hline
\end{tabular}


Considerando a ferramenta mais votada se obteve o seguinte resultado:

Tabela 3 - Ferramenta mais votada.

\begin{tabular}{l|l|l}
\hline Modalidade & \multicolumn{1}{|c|}{ Ferramenta mais votada } & \multicolumn{1}{c}{ Ferramenta } \\
\hline $\begin{array}{l}\text { Professores } \\
\text { do PROEJA }\end{array}$ & $\begin{array}{l}73 \% \text { consideraram } \\
\text { indispensáveis a opção }(\mathrm{K})\end{array}$ & $\begin{array}{l}\text { Conteúdo de estudo complementar para } \\
\text { aprofundamento do tema - leituras } \\
\text { complementares, indicações de sites úteis e } \\
\text { recomendação de bibliografias utilizado em todas } \\
\text { as temáticas, com variação dos tipos. }\end{array}$ \\
\hline $\begin{array}{l}\text { Professores } \\
\text { EAD }\end{array}$ & $\begin{array}{l}80 \% \text { consideraram importante } \\
\text { a opção }(\mathrm{B}) \\
80 \% \text { consideraram importante } \\
\text { a opção }(\mathrm{O})\end{array}$ & $\begin{array}{l}\text { Questionários com as respostas } \\
\text { Repositório com arquivos (em geral) de } \\
\text { apresentações e outros; }\end{array}$ \\
\hline
\end{tabular}

Gráfico - Opção que foi considerado mais importante pelos professores do PROEJA.

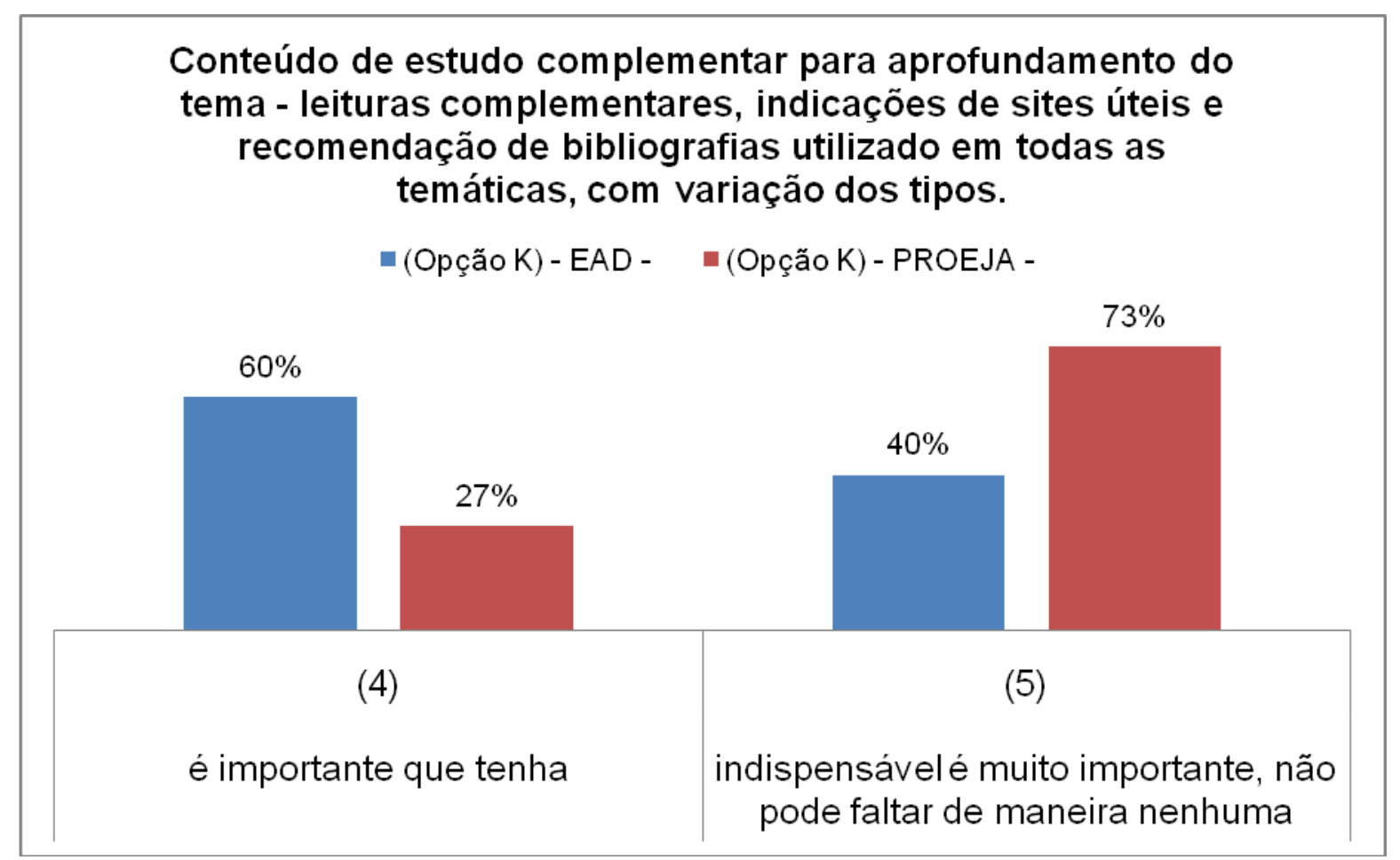

Gráfico 2 - Opções que foram consideradas mais importantes pelos professores do EAD. 
Através da ferramenta mais votada, percebe-se que os professores do PROEJA consideram indispensável que o site tenha conteúdo de estudo complementar para aprofundamento do tema com leituras complementares, indicações de sites úteis e recomendação de bibliografias utilizadas em todas as temáticas com variação dos tipos. Este indicativo mostra uma deficiência a ser levada em consideração: ou está ocorrendo pouca interação por parte deste grupo de professores com as ferramentas disponíveis no mundo virtual (sendo que preferem que o próprio site os auxiliem na indicação de outros sites úteis uma vez que poucos dos entrevistados indicaram algum site que eles próprios indicam para seus alunos), ou há pouca estrutura que proporcione o acesso dos professores e alunos ao mundo virtual de aprendizagem, tornando assim inviável a sua incorporação como proposta complementar no processo de ensino aprendizagem.

Já o grupo de professores do EAD obteve dois resultados com a mesma porcentagem. O primeiro diz respeito ao modo de ensino mais tradicional (questionários com as respostas) e o segundo mais interligado à proposta da facilidade de troca de informações atualizadas proporcionada pela grande rede mundial de computadores (repositório com arquivos em geral de apresentações e outros). Através destas respostas e em conjunto com o quadro comparativo de indicação de ferramentas, pode-se afirmar que essa modalidade de ensino apresenta-se como uma forma de desenvolvimento pessoal, nos quais professores e estudantes podem interagir, virtual e presencialmente em larga escala, por meio da utilização didática das tecnologias da informação e da comunicação e dessa forma necessitam estar mais em contato com as tecnologias apresentadas porque essas fazem parte da dinâmica do processo, ou seja, sem essas tecnologias a modalidade de ensino EAD seria inviável.

Pela avaliação da questão dois, ao serem questionados sobre a utilização de sites indicando-os como forma complementar para os alunos ampliarem seus conhecimentos ou até mesmo para tirar dúvidas das aulas ministradas, percebe-se que a maioria dos professores do PROEJA afirmam não utilizarem muitas tecnologias entre as elencadas na questão um (1), e poucos indicaram algum tipo de site utilizado por eles nesta pesquisa. Já os professores do EAD, além do ambiente virtual que utilizam a plataforma MOODLE, eles indicam vários outros sites para os alunos aprofundarem os seus conhecimentos. 
Ao avaliar a questão três (onde se perguntava se eles acreditavam que o conteúdo da internet poderia auxiliar seus alunos a aprender mais sobre os assuntos ministrados), a grande maioria respondeu que acha muito importante utilizar a internet como apoio no ensino-aprendizagem, mas ressalta a necessidade de haver uma filtragem prévia do conteúdo por parte dos próprios professores. Além disso, a maioria afirma que não utiliza ainda mais as tecnologias disponíveis por falta de conhecimento ou acesso, lembrando que a estrutura física disponível nas escolas e a realidade vivida por muitos dos alunos ainda se apresentam como barreiras para o crescimento desta nova forma de ensinar e aprender.

\section{CONCLUSÃO}

A partir desta pesquisa percebe-se que é fundamental para que se intensifique a utilização de tecnologias da informação como auxilio na expansão no ensino e aprendizagem fornecer suporte na preparação do professor para exercer suas funções e aproveitar ao máximo os recursos oferecidos pela plataforma. O professor deve inicialmente passar pela experiência deste contato com o ambiente virtual para posteriormente expandir essa experiência para seus alunos.

Percebe-se também que a cultura educacional está cada vez mais avançando no caminho de aceitação e incorporação das ferramentas disponíveis na internet, como forma de ampliar os horizontes da sala de aula para além dos muros da escola. No entanto, é uma realidade que a falta de estrutura física, logística e de apoio a aprendizagem e treinamento para os professores apresenta-se como a maior barreira para a expansão deste novo jeito de aprender e ensinar.

Enfim, a tecnologia da informação aparece como uma ferramenta importante no processo de construção de Políticas Públicas de Educação, contribuindo para inclusão social e expansão da educação no país.

A introdução dessas novas tecnologias, com enfoque na internet, colabora de forma bastante notória para a expansão da utilização de ambientes virtuais de ensino - aprendizagem, uma vez que o acesso à informação e à educação tornaram-se necessidades prioritárias no mundo contemporâneo, sendo a 
educação globalizada o auge almejado por toda sociedade que visa 0 desenvolvimento.

\section{Referências}

BARCELOS,N. Internet: um novo paradigma na educação de jovens e adultos. Porto Alegre/ RS, 2009.

BÖELTER, Ana Elisa. A EJA e a tecnologia da informação e comunicação (TIC). São Vicente do Sul/RS, 2009.

BRASIL. Lei № 11.741/2008 - Lei de Diretrizes e Bases da Educação Nacional. Disponível em: <http://www.planalto.gov.br/ccivil_03/_Ato20072010/2008/Lei/L11741 .htm\#art1 >. Acesso em: 28 set. 2010.

FRANCO, M.A.; CORDEIRO, L. M.; CASTILLO, R. A. F. O ambiente virtual de aprendizagem e suas incorporação na Unicamp. Educação e Pesquisa, São Paulo, FE/USP, v. 29 n. 2, 2003.

FREIRE, Paulo. Ação cultural para a liberdade e outros escritos. Rio de Janeiro: Paz e Terra. 6 Ed. 1982, pp. 09-12.

FREIRE, Paulo. Pedagogia da Autonomia: saberes necessários à prática educativa. São Paulo: Paz e Terra, 2002.

LÉVY, P. Cibercultura (trad. Carlos Irineu da Costa). São Paulo: Editora 34, 1999, $264 p$. 
MORAN,J.M.; MASETTO,M.T.; BEHRENS, M.A. Novas tecnologias e mediação pedagógica. 14. Ed. São Paulo: Papirus Editora, 2008.

SÉRAPHIN ALAVA \& COLABORADORES. Ciberespaço e Formações abertas Rumo a Nova Prática Educacional; Tradução Fátima Murad. Porto Alegre: Artmed Editora Ltda; 2002.

VALENTE, J. A.; Organizador. O Computador na Sociedade do Conhecimento. Campinas, SP: UNICAMP/NIED, 1999.

${ }^{1}$ Especialista em Educação Profissional Integrada à Educação Básica na Modalidade de Educação de Jovens e Adultos; Professor do Ensino Básico, Técnico e Tecnológico; Instituto Federal de Educação Ciência e Tecnologia do Tocantins (IFTO) campus Palmas.anderson@ifto.edu.br;

${ }^{2}$ Especialização em Engenharia do Produto e Design; Professor do Ensino Básico, Técnico e Tecnológico; Instituto Federal de Educação Ciência e Tecnologia do Tocantins (IFTO) campus Gurupi. anamaria@ifto.edu.br;

${ }^{3}$ Mestre em Ciência da Computação; Professor do Ensino Básico, Técnico e Tecnológico; Instituto Federal de Educação Ciência e Tecnologia do Tocantins (IFTO) campus Palmas. focking@ifto.edu.br;

RECEBIDO EM 04.07.2011

APROVADO EM: 22.07.2011 